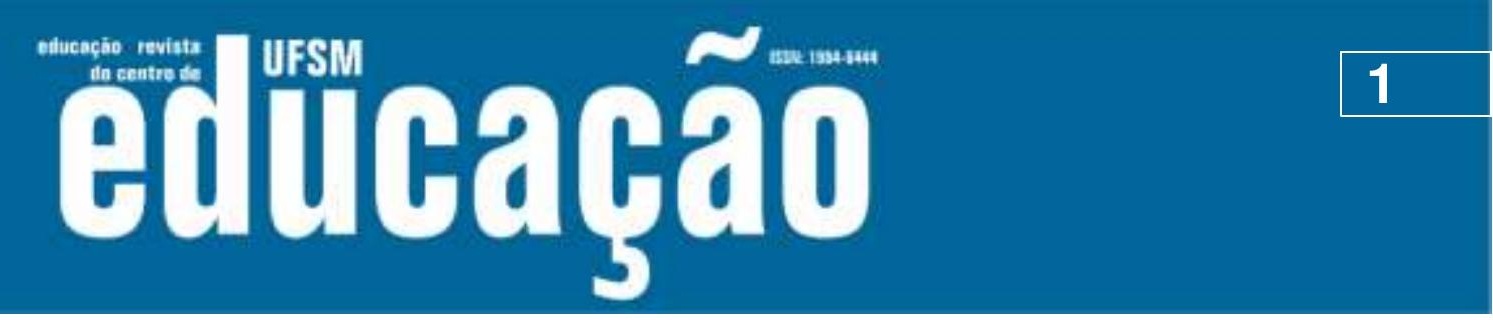

ISSN: 1984-6444 | http://dx.doi.org/10.5902/1984644434678

\title{
Manifestações do "quase-mercado" nas avaliações externas e em larga escala
}

"Quasi-market" manifestations in external and large scale evaluations

\author{
Fabio Perboni \\ Universidade Federal da Grande Dourados \\ Andréia Nunes Militão \\ Universidade Estadual do Mato Grosso de Sul \\ Cristiano Amaral Garboggini Di Giorgi \\ Universidade do Oeste Paulista
}

\section{RESUMO}

O artigo em tela parte de pesquisa empírica sobre a implementação das avaliações externas e em larga escala nas redes de educação básica dos estados brasileiros, no período de 2003 a 2014. Objetiva analisar a presença das fundações e empresas privadas nos processos de formulação e implementação das avaliações externas e em larga escala. Ancorada em abordagem qualitativa, analisou-se documentos produzidos no âmbito dos 26 estados brasileiros e do Distrito Federal, que permitiram indiciar a existência de um mercado ou "quase-mercado" das avaliações. Configurase, portanto, uma das características marcantes das políticas educacionais nas últimas décadas que combinam ao mesmo tempo, maior controle do Estado e a presença crescente da lógica de mercado e de agentes privados na organização dessas mesmas políticas. Depreende-se, assim, que empresas e fundações são responsáveis pela operacionalização das avaliações nos sistemas estaduais, constituindo um "mercado das avaliações", seja no âmbito do controle dos processos que adquire uma lógica privada, seja no controle da expertise para implementação desses processos, que também estão fora do controle da gestão dos sistemas de ensino. Em um cenário de restrições orçamentárias, alerta-se que no contexto internacional processos de financeirização da educação estão mais presentes e podem desencadear implicações futuras para essas relações que aqui denominamos de "quase-mercado".

Palavras-chave: Avaliação externa e em larga escala; Quase-mercado; Mercado das avaliações. 


\section{Autuaŗão}

ISSN: 1984-6444 | http://dx.doi.org/10.5902/1984644434678

da Educação Nacional de 1996 abriu-se a possibilidade formal de "empresas lucrativas" adentrarem o mercado educacional.

Tem-se, assim, a ampliação da atuação direta de empresas na oferta educacional, além de outras atividades como a venda de materiais pedagógicos e "[...] 'pacotes' educacionais, que incluem aluguel de marca, pelo mecanismo de franquias, avaliação e formação em serviço do professor [...]" (OLIVEIRA, 2009, p. 740). Alguns estudos (SILVA, 2008; ADRIÃO \& PERONI, 2009;, PERONI, OLIVEIRA \& FERNANDES, 2009) indicaram, ainda, outras iniciativas que envolvem gestão de escolas ou do conjunto dos sistemas de ensino por entidades não-estatais, privadas com ou sem fins lucrativos.

Neste cenário em que se acentua um discurso de competitividade educacional, a ampliação dos processos de avaliação externa e em larga escala ${ }^{1}$ adquiriu centralidade vinculando, automaticamente, a melhoria da qualidade da educação à elevação dos índices derivados dos resultados dos alunos nestas provas. Os processos avaliativos em larga escala não são, à priori, uma manifestação neoliberal, uma vez que podem assumir variadas configurações. Assim, não se pode antecipadamente vincular as avaliações externas a uma determinada concepção, sem desnudar os elementos que embasam sua formulação e implementação.

Aponta-se para a emergência da naturalização de uma suposta "cultura da avaliação", que incorpora os instrumentos avaliativos externos às práticas cotidianas. Segundo Ristoff (1994, p. 60), a cultura da avaliação pode ser compreendida como "[...] um conjunto de valores acadêmicos, atitudes e formas coletivas de conduta que tornem o ato avaliativo parte integrante do exercício diuturno de nossas funções [...]". Embora controversa, essa ideia está presente no discurso oficial daqueles que formulam as políticas educacionais em diversos contextos. Apesar da imprecisão conceitual do termo, esse fenômeno expressa alterações nas concepções sobre avaliação presentes nas escolas de educação básica.

\footnotetext{
${ }_{1}^{1}$ Neste texto utilizou-se o termo avaliações externas e em larga escala por considerar que expressa de forma precisa os processos de avaliação instituídos no Brasil, que se caracterizam por serem pensados e formulados 'fora das escolas' e se direcionarem a amplo contingente de alunos e escolas que abrangem praticamente toda a Educação Básica.
} 


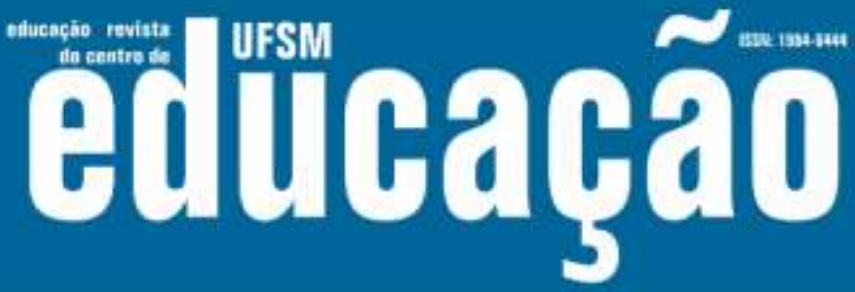

ISSN: 1984-6444 | http://dx.doi.org/10.5902/1984644434678

Esse fator anuncia a pertinência dos estudos sobre os arranjos entre o Estado e as organizações privadas em relação a estas avaliações, que envolvem diferentes processos, tais como: elaboração e aplicação das provas, divulgação dos resultados, formação de equipes técnicas e de docentes para compreensão dos mecanismos das provas e seus resultados e toda a logística e expertise que envolve cada uma dessas etapas.

Constata-se na produção sobre a temática o aumento do foco no uso de resultados em determinadas escolas, sistemas ou ainda relacionadas às disciplinas específicas, como mostram os trabalhos de Bauer (2012), Martins e Sousa (2012), Silva (2013), Bauer e Reis (2014). Uma segunda constatação indica que são relativamente escassos estudos mais amplos sobre dados empíricos das avaliações em todo o Brasil, procurando desvendar mecanismos de funcionamento e tendências mais gerais. Com esse escopo, destacamos, dentre outros, os trabalhos de Freitas (2007), Lopes (2007), Sousa e Oliveira (2010), Werle (2012), Sverdlick (2012), Bauer et. al. (2015), Alavarse, Machado e Arcas (2015), Perboni (2016). Este artigo se insere neste segundo grupo, ao propor uma reflexão mais ampla sobre a influência das fundações e empresas nas avaliações externas e em larga escala a partir de dados empíricos coletados em todos os sistemas estaduais de ensino do Brasil, abrangendo um período de 12 anos.

As reflexões aqui apresentadas decorrem da investigação de dados empíricos acerca das avaliações externas e em larga escala instituídas pelos sistemas estaduais de educação a partir de 2002. Ancorada em pesquisa documental, analisou-se proposições dos 26 estados e do Distrito Federal, identificando em 21 deles a existência de avaliações próprias dos sistemas estaduais, demonstrando a abrangência dessa prática no âmbito das políticas educacionais.

Parte-se de pesquisa mais ampla iniciada em 2012 e finalizada em 2016, com objetivo de investigar diferentes aspectos do processo de expansão das avaliações externas e em larga escala nas redes estaduais de educação básica, orientada por alguns questionamentos como: Quem avalia? O que e quem é avaliado? Quais são os usos dessas avaliações? Quais as consequências de seus resultados para os envolvidos no processo de ensino? Dentre os achados dessa pesquisa maior, 


\section{OFus

ISSN: 1984-6444 | http://dx.doi.org/10.5902/1984644434678

localizou-se a forte presença de consultorias e assessorias na condução dos processos avaliativos, aspecto desenvolvido no presente trabalho.

A opção pelo uso da pesquisa documental explica-se por esta permitir apreender as avaliações próprias dos estados brasileiros, pois para se consolidarem ou serem implementadas, dependem de uma série de mecanismos de publicização, tais como manuais, orientações e divulgação; também necessitam de uma regulamentação por meio de normatizações que envolvem leis, decretos e resoluções. Todo esse volume de informações constituem-se em fontes que necessitam ser selecionadas, sistematizadas, organizadas e analisadas de forma a compor um quadro coerente das avaliações externas e em larga escala nos estados do Brasil, de forma que possam ser identificados padrões e tendências passíveis de serem comparados. Os dados foram coletados por meio dos endereços eletrônicos das Secretarias Estaduais de Educação.

Dessa forma, este texto problematiza o papel das fundações e empresas privadas nos processos de formulação e implementação das avaliações externas e em larga escala.

Para desenvolver esse intento organizamos duas seções. Na primeira parte, discutimos os conceitos de 'mercado', 'quase-mercado' e problematizamos o protagonismo assumido pelas assessorias e consultorias na definição das políticas educacionais, notadamente destinadas à elaboração e aplicação das avaliações externas e em larga escala. A segunda seção examina dados empíricos das avaliações externas e em larga escala dos sistemas estaduais, identificando as parecerias instituídas para viabilizar as avaliações.

\section{O mercado e o quase-mercado no campo educacional}

A materialização da concepção neoliberal na política educacional manifesta-se pela introdução de mecanismos de mercado, propriamente dito, na organização dos sistemas educacionais. Essa inserção ocorre a partir das reformas instituídas nos países centrais que procuraram redefinir o papel do Estado. Le Grand (1991, p. 1260) assevera que "[...] all these reforms had a fundamental similarity: the introduction of 


\section{L

ISSN: 1984-6444 | http://dx.doi.org/10.5902/1984644434678

convencionou chamar de "quase-mercado", manifesta-se nas políticas educacionais de formas variadas.

Cabe ressaltar que se existe certo consenso em torno da acepção de "quasemercado", caracterizada pela introdução de mecanismos privados na gestão pública. Há, de outro lado, profícuo debate sobre os limites entre o neoliberalismo e a Terceira Via defendida, entre outros, por Giddens (1996), que se manifestam nas discussões sobre a Nova Gestão Pública (New Public Management) e nas relações entre o Estado e outros agentes na oferta da educação.

Depreende-se que após a crise de 2008 se acirraram os mecanismos de "quase-mercado", inaugurando uma nova fase do neoliberalismo, conforme assevera Mcgimpsey (2017):

[...] in late neoliberalism austerity, social investment and localism operate in conjunction. Beyond fiscal constraint, this conjunction serves to move social policy on from 'quasi-marketisation' to reflect more closely the logic and forms of finance capital. The effects of this change can be seen in the reconstitution of 'value' in public services, how capital is distributed, and in the subjectivating force of policy4. (MCGIMPSEY, 2017, p. 64)

Nesta perspectiva, o Estado deixa cada vez mais de ser o executor, assumindo progressivamente o papel de "Estado-regulador" e "Estado-avaliador" instituindo-se, assim, mecanismos de gestão privada nas instituições públicas. Concomitantemente, criam-se mecanismos de controle e responsabilização mais amplos e requintados. A avaliação é, pois, elemento essencial nesta vertente. A estruturação de "quasemercados" implica, necessariamente, uma alta regulamentação governamental, na qual os sistemas de avaliação, projetados para medir e fiscalizar, são indispensáveis.

Orellana (2018, p. 03), identifica no sistema educacional chileno, dentre outros elementos, a escolha das escolas pelas famílias em um contexto de competição e privatização. $\mathrm{O}$ autor destaca que "[...] el estudio de la elección de escuela ha pasado

\footnotetext{
4 "[...] no final do neoliberalismo, a austeridade, o investimento social e o localismo operam em conjunto. Além da restrição fiscal, essa conjunção serve para mover a política social da "quase-mercantilização" para refletir mais de perto a lógica e as formas do capital financeiro. Os efeitos dessa mudança podem ser vistos na reconstituição do 'valor' nos serviços públicos, como o capital é distribuído e na força de subjetivação da política”. (MCGIMPSEY, 2017, p. 64, tradução nossa).
} 


\section{Usm

ISSN: 1984-6444 | http://dx.doi.org/10.5902/1984644434678

a ser parte de las preocupaciones sobre cómo se produce y mantiene la desigualdad en educación". 5

\section{Avaliações externas e em larga escala no contexto do estados brasileiros}

A consolidação das avaliações externas e em larga escala na educação básica em âmbito nacional foi acompanhada pela diluição das fronteiras entre o público e o privado. Esse fenômeno, que não é exclusivo ao Brasil, materializa-se na atuação das assessorias. Entretanto, antes de empreender a análise do caso específico do Brasil, torna-se importante localizar o papel das assessorias no âmbito da atuação do Estado.

À primeira vista, a assessoria deteria o saber, mas não o poder, ou seja, teria uma legitimidade cognoscitiva sobretudo centrada na selecção dos meios ou recursos mais eficazes e eficientes com vista a alcançar um determinado fim ou objectivo, mas faltar-Ihe-ia a legitimidade política para tomar a decisão final e para escolher entre fins ou objetivos alternativos. (LIMA, 2011, p. 118)

Lima (2011) assevera que a inserção das assessorias no setor público podem indicar certa subalternidade e em outro extremo a competência:

\footnotetext{
Com efeito, a assessoria remete, por um lado, para uma certa subalternidade de funções (de apoio, auxílio ou assistência a alguém) e, por outro lado, para o poder do conhecimento, para a competência assessorial legitimada em termos periciais, isto é, para o estatuto do especialista que estuda, traça cenários, planeia, prepara a decisão, aconselha os decisores políticos legítimos e os superiores hierárquicos nas organizações formais. (LIMA, 2011, p. 118)
}

A presença de empresas na condução de processos avaliativos dos sistemas municipais e estaduais de educação reveste-se de caráter técnico, contudo não se pode ignorar que toda ação técnica comporta uma decisão política, pois seus resultados definem e/ou influenciam a tomada de decisões relativas às políticas educacionais. As consultorias ${ }^{6}$ atuam no Brasil de forma crescente a partir de "[...] planos estratégicos, reengenharia institucional, elaboração de projetos de curso,

\footnotetext{
${ }^{5}[\ldots]$ o estudo da escolha da escola tornou-se parte das preocupações sobre como a desigualdade na educação é produzida e mantida (ORELLANA, 2018, p. 03, tradução nossa).

${ }^{6} \mathrm{O}$ termo assessoria utilizado por Lima (2011) para o contexto português corresponde a expressão "consultoria" mais recorrente para o contexto brasileiro. Entre as consultorias mais expressivas que atuam no Brasil, Oliveira (2009) destaca a P. R. Consultores, do ex-ministro da Educação e exsecretário estadual de Educação de São Paulo, Paulo Renato Souza, a Lobo \& Associados, do exreitor da Universidade de São Paulo, Roberto Leal Lobo e Silva Filho, a CM Consultores e a Hoper Educacional.
} 


\section{Autuaŗão}

ISSN: 1984-6444 | http://dx.doi.org/10.5902/1984644434678

programas de auto-avaliação, marketing institucional, desenvolvimento de sistemas próprios de crédito educativo" (OLIVEIRA, 2009, p. 742).

Com relação às políticas educacionais direcionadas à educação básica no contexto brasileiro, denota-se intensa presença da ação estatal que, em algumas esferas, é mais centralizada do que em décadas passadas como, por exemplo, na articulação entre as avaliações externas e em larga escala e as políticas curriculares, com clara diminuição da autonomia docente em favor do controle estatal.

O controle sobre as políticas educacionais formalmente exercido pelo poder público tem marcada presença da lógica de mercado na medida em que o Estado contrata a expertise de agentes privados para a formulação e implementação de diferentes ações no campo das políticas educacionais.

$\mathrm{Na}$ sequência discute-se, a partir de pesquisa documental, a influência dos agentes externos na definição das políticas de avaliação das redes estaduais de educação básica implementadas no período de 2002 a 2014.

As avaliações externas e em larga escala adotadas em âmbito nacional, fenômeno recente na história da educação brasileira, induziram a instituição por parte dos governos estaduais de avaliações próprias. Soma-se a esse aspecto um deslocamento da centralidade das avaliações da aprendizagem para as avaliações externas como parâmetro de qualidade educacional, fenômeno estudado por diferentes autores (OLIVEIRA, 2007; CHIRINEA \& BRANDÃO, 2015; TERRASECA, 2016) que demonstram as implicações decorrentes dessa mudança para as escolas e para os sistemas de ensino. Esse processo não é linear nos sistemas estaduais de ensino, ao contrário, é caracterizado por descontinuidades, seja via mudanças de nomenclaturas, seja por mudanças nos processos. Alguns estados mantiveram a denominação, mas modificaram profundamente os processos. Outros, por sua vez, alteraram o nome das avaliações sem, no entanto, modificar significativamente sua configuração. Também é comum a descontinuidade na aplicação das provas por ocasião dos pleitos eleitorais ou mesmo o lapso temporal de um mesmo governo. Esses aspectos dificultam o tratamento das especificidades das avaliações externas e em larga escala neste espaço, contudo é possível identificar um movimento acelerado de implementação destas avaliações a partir do início do século XXI. 


\section{Tusm Alltapato}

ISSN: 1984-6444 | http://dx.doi.org/10.5902/1984644434678

$\mathrm{Na}$ década de 1990 apenas seis estados possuíam avaliações próprias na educação básica: Ceará, Mato Grosso do Sul, Paraná, Rio Grande do Sul, São Paulo e Bahia (LOPES, 2007). Num rápido processo de expansão, outros nove estados instituíram suas avaliações no intervalo de 2000 a 2002 (Espírito Santo, Goiás, Maranhão, Minas Gerais, Pernambuco, Rio de Janeiro, Alagoas, Tocantins e Acre). Considerando, ainda, que Mato Grosso do Sul e Bahia descontinuaram o emprego das provas, em 2003, 13 estados aplicaram provas para medir o nível de proficiência de seus alunos na educação básica. A investigação feita pelo Grupo de Avaliação e Medidas Educacionais (GAME, 2011) revelou a existência de avaliações externas em 18 estados. Já no mapeamento feito por Sousa e Oliveira (2010) constatou-se 19 estados com avaliações externas. Dados mais recentes de Perboni (2016) indicaram que apenas seis estados da Federação não possuíam seus sistemas próprios no ano de 2014, portanto, existiam avaliações próprias em 20 estados e no Distrito Federal sendo que 15 destes implementaram-nas já no século XXI. O Quadro 01 sintetiza essas informações.

Quadro 01 - Características das Avaliações Estaduais

\begin{tabular}{|c|c|c|c|c|c|c|}
\hline Região & $\begin{array}{l}\text { Esta } \\
\text { do }\end{array}$ & Avaliação & $\begin{array}{c}\text { Ano de } \\
\text { Criação }\end{array}$ & $\begin{array}{l}\text { Bônus/ } \\
\text { Prêmio }^{8}\end{array}$ & $\begin{array}{l}\text { Indice } \\
\text { Próprio }\end{array}$ & $\begin{array}{c}\text { Realização das } \\
\text { avaliações }^{9}\end{array}$ \\
\hline \multirow{7}{*}{$\begin{array}{l}\text { Região } \\
\text { Norte }\end{array}$} & $A C$ & SEAPE & 2009 & Não & & SEE \\
\hline & $\mathrm{AP}$ & - & - & - & - & - \\
\hline & AM & SADEAM & 2008 & Sim & IDEAM & $\begin{array}{l}\text { CESP-UnB } \\
\text { CAED-UFJF }\end{array}$ \\
\hline & PA & SISPAE & 2013 & Não & & CAED-UFJF \\
\hline & $\mathrm{RO}$ & SAERO & 2012 & Não & & CAED-UFJF \\
\hline & $\mathrm{RR}$ & - & - & - & - & - \\
\hline & TO & SALTO & 2011 & Sim & & SEE \\
\hline \multirow{3}{*}{$\begin{array}{l}\text { Região } \\
\text { Nordeste }\end{array}$} & $A L$ & SAVEAL & 2001 & Não & IDEAL & $\begin{array}{c}\text { AVALIA } \\
\text { CAED-UFJF }\end{array}$ \\
\hline & BA & SABE & 2007 & Não & & CAED-UFJF \\
\hline & CE & SPAECE & 1992 & Sim & IDE & CAED-UFJF \\
\hline
\end{tabular}

\footnotetext{
${ }^{7}$ Ressaltamos que algumas avaliações tem o ano de criação que não corresponde ao modelo atual de aplicação das provas quanto a regularidade e anos/séries envolvidos. Assim, o SAVEAL (AL) só passou a ser regularmente aplicado após 2011. O SPAECE (CE) só adquiriu seu formato atual em 2003; o PAEBES (ES) passou a ser regularmente aplicado após 2008 e alguns outros estados possuem várias avaliações, considerada no quadro o nome do conjunto de avaliações, denominados de sistemas como, por exemplo, MG e BA. No caso da substituição de uma avaliação por uma nova em formato e denominação, optamos por indicar a mais recente como o caso do RS, do PR e do DF.

8 Os estados do Rio de Janeiro e do Tocantins têm mecanismos de vinculação da remuneração dos profissionais da educação com os resultados do IDEB.

${ }^{9}$ No caso dos estados em que consta a avaliação organizada pela SEE, não significa que o mesmo realize todo o processo, mas ao menos as partes mais significativas, como no caso de São Paulo que contrata a VUNESP para impressão, distribuição e correção das avaliações.
} 


\section{D usm

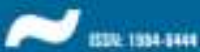

ISSN: 1984-6444 | http://dx.doi.org/10.5902/1984644434678

\begin{tabular}{|c|c|c|c|c|c|c|}
\hline & MA & SIMADE & Projeto & Não & - & - \\
\hline & PB & SAEPB & 2012 & Não & & CAED-UFJF \\
\hline & $\mathrm{PE}$ & SAEPE & 2008 & Sim & IDEPE & CAED-UFJF \\
\hline & $\mathrm{PI}$ & SAEPI & 2011 & Não & & CAED-UFJF \\
\hline & $\mathrm{RN}$ & - & - & - & - & - \\
\hline & SE & SAPED & $2004^{10}$ & Sim & & SEE \\
\hline \multirow{4}{*}{$\begin{array}{l}\text { Região } \\
\text { Centro- } \\
\text { Oeste }\end{array}$} & DF & ADEE & 2011 & Não & & SEE \\
\hline & GO & SAEGO & 2011 & Não & IDEGO & $\begin{array}{c}\text { CAED-UFJF } \\
\text { INEP }\end{array}$ \\
\hline & MS & SAEMS & 2003 & Não & & CAED-UFJF \\
\hline & MT & - & - & - & - & - \\
\hline \multirow{4}{*}{$\begin{array}{l}\text { Região } \\
\text { Sudeste }\end{array}$} & ES & PAEBES & 2004 & Sim & IDE & CAED-UFJF \\
\hline & MG & SIMAVE & 2000 & Sim & & $\begin{array}{l}\text { CEALE-UFMG } \\
\text { Inst. Avaliar } \\
\text { CAED-UFJF }\end{array}$ \\
\hline & RJ & SAERJ & 2008 & Sim & & CAED-UFJF \\
\hline & SP & SARESP & 1996 & Sim & IDESP & SEE \\
\hline \multirow{3}{*}{$\begin{array}{l}\text { Região } \\
\text { Sul }\end{array}$} & $\mathrm{PR}$ & SAEP & 2012 & Não & & CAED-UFJF \\
\hline & RS & SEAP & 2011 & Não & & CAED-UFJF \\
\hline & SC & - & - & - & 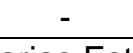 & \\
\hline
\end{tabular}

Fonte: Elaborado pelos autores a partir de dados das Secretarias Estaduais de Educação, 2016.

A simultaneidade da criação das avaliações nos estados pode ser explicada, em parte, pela cooperação estabelecida entre o INEP-MEC para sua implantação ou desenvolvimento, pela simples preexistência do modelo desenvolvido nacionalmente, ou ainda, considerando o contexto mais recente, a partir de consultoria prestada por empresas, fundações ou centros de pesquisa como o Centro de Políticas Públicas e Avaliação da Educação (CAed), vinculado à Faculdade de Educação da Universidade Federal de Juiz de Fora (UFJF), que se destaca pela significativa atuação em 16 estados.

A utilização dos resultados desses processos avaliativos em larga escala depara-se, no país, com uma intensa disputa ideológica. Se há, de um lado, "[...] a expectativa de uma gestão de sistema ancorada em uma racionalidade instrumental, com perspectiva de gerar maior eficiência [...]", de outro, esta não se ampara na ideia também difundida da "[...] autonomia dos processos educativos no âmbito da escola, enfatizando processos de autoavaliação [...]" (SOUSA; OLIVEIRA, 2010, p. 798).

Esses elementos podem ser identificados nas ações desencadeadas pelo governo federal que deram centralidade ao processo avaliativo e incentivaram estados e municípios a adotarem mecanismos para sua ampliação, exemplificado pelo

${ }^{10}$ Avaliação não vigente na atualidade. 


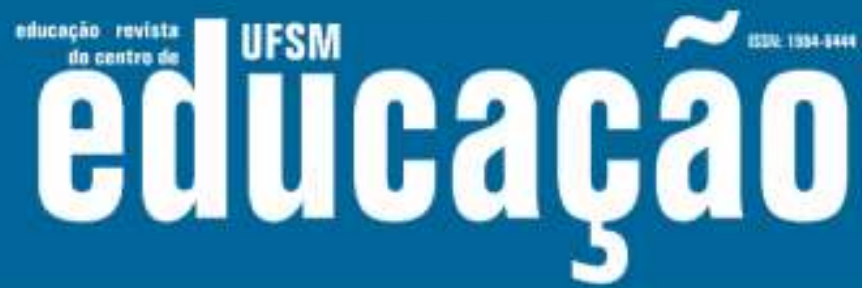

ISSN: 1984-6444 | http://dx.doi.org/10.5902/1984644434678

engajamento do governo e entidades da sociedade civil na implementação do IDEB, tal como o Compromisso Todos pela Educação, desdobramento do Plano de Desenvolvimento da Educação (PDE) que "[...] propõe a articulação de esforços para a melhoria da qualidade [...]" medida pelo novo índice, afirmando que "Os sistemas municipais e estaduais que aderirem ao Compromisso seguirão 28 diretrizes pautadas em resultados de avaliação de qualidade e de rendimento dos estudantes" (BRASIL, 2007).

A questão do uso dos resultados das avaliações como mecanismo para melhoria da qualidade da educação precisa ser problematizada a partir do significado dessas avaliações e índices sobre a prática educativa. Oliveira (2007) pondera, que critérios e padrões "[...] podem, facilmente, simplificar problemas complexos pela utilização de indicadores com potencial de provocar mudanças [...]", porém, estas podem não ser as indicadas nos documentos oficiais, a "[...] observação indica a necessidade de uma reflexão mais cuidadosa sobre os usos (e abusos!) do Índice de Desenvolvimento da Educação Básica - Ideb" (Oliveira, 2007, p. 33).

Uma das iniciativas capazes de potencializar um maior envolvimento das escolas reside nas experiências que agregam às provas respondidas pelos alunos outros elementos, por exemplo, a auto avaliação institucional "[...] com base na compreensão de que tal sistemática teria poder, entre outras atribuições, de gerar envolvimento e compromisso de todos com a melhoria da qualidade da educação [...]" (SOUSA; OLIVEIRA, 2010, p. 809). Para os autores, os estados do Ceará e do Paraná seriam exemplos desse modelo, entretanto, identificamos que essas experiências foram descontinuadas, sinalizando o caráter marginal dessas práticas. ${ }^{11}$

Ao contrário desse processo mais reflexivo, os modelos das avaliações externas e em larga escala e seus usos continuam fortemente ou, quase que exclusivamente, baseadas nas provas que medem a proficiência dos alunos em conhecimentos de português e matemática. Identificamos a expansão do uso de mecanismos que se colocam exatamente no caminho oposto, ao intensificar a relação

\footnotetext{
${ }^{11} \mathrm{Em}$ 2011, o estado do Rio Grande do Sul implementou modelo com um processo diferenciado que agrega outras informações aos resultados das provas de proficiência denominado Sistema Estadual de Avaliação Participativa do Rio Grande do Sul.
} 


\section{HEM

não possui um corpo técnico capacitado para conduzir o processo, comumente terceirizado para empresas e fundações, que assumem as diversas etapas de forma integral ou parcial, com diferentes graus de apropriação pelas equipes técnicas dos estados.

À esse processo denominamos "mercado das avaliações", por compreender que esse termo caracteriza de forma ampla as relações estabelecidas entre os estados e as empresas ou entidades que organizam as avaliações. Independentemente do formato adotado, predomina na prática uma mesma concepção calcada na lógica de mercado, na padronização e na apresentação da proficiência dos alunos na forma de escalas e/ou índices que representariam a síntese da qualidade da educação.

Por outro lado, a importância que as avaliações assumem nas políticas educacionais e sua dimensão em termos financeiros se constitui realmente em um atrativo mercado que envolve, além da logística da elaboração, aplicação e correção das provas outros elementos como a divulgação dos resultados, cursos, palestras e materiais explicativos para pessoal técnico das secretarias, docentes, gestores, a comunidade em geral e toda a sociedade.

No cenário atual, denota-se a hegemonia do CAEd, com presença na maioria dos estados, atuando como parceiro em parte ou em todo o processo que envolve as avaliações próprias dos estados. A ação desta fundação tem priorizado mais aspectos da formação continuada dos profissionais das redes estaduais visando ao preparo de profissionais da educação para a apropriação dos mecanismos que fundamentam suas avaliações de forma a instrumentalizá-los para utilizar esses resultados.

O Quadro 02 explicita os dados relativos à participação do CAEd no conjunto de avaliações estaduais. Percebe-se que, apenas quatro estados têm avaliações próprias sem o apoio do CAEd, aspecto que impressiona, sobretudo, pela constatação da presença desta instituição em ao menos parte dos processos de 17 estados pesquisados. Observa-se que estados com equipes consolidadas recorrem à assessorias e terceirizam parte dos processos avaliativos, como Minas Gerais e Ceará que têm parceria com o CAEd e São Paulo que tem contrato com a VUNESP. 


\section{THEM

ISSN: 1984-6444 | http://dx.doi.org/10.5902/1984644434678

Quadro 02 - Estados com participação do CAEd na realização das provas

\begin{tabular}{|l|c|}
\hline \multicolumn{1}{|c|}{ Grupo } & Estados \\
\hline $\begin{array}{l}\text { Avaliações com participação do CAEd-UFJF em } \\
\text { sua organização }\end{array}$ & $\begin{array}{c}\text { AC, AL, AM, BA, CE, ES, GO, MG, MS, } \\
\text { PA } 12, \text { PB, PR, PE, PI, RJ, RS, RO }\end{array}$ \\
\hline $\begin{array}{l}\text { Estados com avaliações próprias sem a } \\
\text { participação do CAEd }\end{array}$ & AL, DF, SP, TO \\
\hline Estados sem avaliação própria & AP, MA, MT, RN, RR, SC \\
\hline
\end{tabular}

Fonte: Elaborado pelos autores a partir de dados do CAED, 2014.

A presença do CAEd nos estados confere as avaliações um alto grau de padronização que pode ser identificado, por exemplo, no refinamento técnico das mesmas, elaboradas a partir do uso da Teoria de Resposta ao Item (TRI), da divulgação dos resultados, e do esforço de formação de técnicos e docentes das redes estaduais para compreenderem as concepções e mecanismos que embasam a elaboração da prova. As formações denominadas de oficinas de apropriação de resultados têm, em sua maioria, um formato de cursos semipresenciais ou totalmente à distância. Nesta ocasião, além da devolutiva dos resultados com a divulgação e interpretação dos dados, organiza-se também formação envolvendo temas do processo da prova como sua formulação a partir de matrizes de referência, os significados dos índices entre outros aspectos.

Em relação à formação, constata-se que as propostas para as "oficinas de apropriação de resultados" ${ }^{13}$, têm estrutura parecida em todos os estados, variando apenas em aspectos referentes à abrangência do curso que em alguns estados envolvem apenas gestores e as equipes técnicas das secretarias, enquanto em outros, amplia essas oficinas para os gestores escolares ou ainda para parcela dos docentes.

Entre os tópicos constantes nessas oficinas destacam-se orientações aos gestores que devem atuar como multiplicadores. Adquire ênfase a explicitação dos elementos da prova, envolvendo explicações sobre a matriz de referência, a elaborações dos itens da prova com "enunciado, suporte, comando, alternativas de resposta (gabarito e distratores)" e também a interpretação dos resultados com

\footnotetext{
${ }^{12}$ No ano de 2014, por meio de um processo licitatório, a VUNESP substituiu o CAEd, passando a ser a instituição responsável pelo processo de formulação, aplicação e correção das provas do Estado do Pará.

${ }^{13}$ Curso oferecido para os gestores da Rede Estadual do Rio Grande do Sul no ano de 2014, com carga horária total de $40 \mathrm{~h}$.
} 


\section{Lusm

ISSN: 1984-6444 | http://dx.doi.org/10.5902/1984644434678

apresentação dos gráficos de acerto por descritor, associado com a matriz de referência. Ainda apresenta o conceito de proficiência como "o traço latente do indivíduo, a aptidão" (RIO GRANDE DO SUL, 2014). O curso conta com um roteiro orientador, bastante prescritivo, para os gestores utilizarem no trabalho com as escolas, como demonstra-se no segmento abaixo:

\footnotetext{
- Ler o resultado da escola fazendo uma relação com a escala, explicando os níveis de proficiência de 25 em 25 pontos, fazendo uma ligação com a construção da escala (altura de uma pessoa).

- Fazer a leitura da escala na vertical (traçar a reta da proficiência e passar pelas habilidades que 0 aluno ainda não desenvolveu, já começou a desenvolver ou consolidou) e na horizontal (o desenvolvimento e o grau de complexidade da habilidade).

- Ressaltar a necessidade de participação dos alunos nos resultados, quanto maior a participação dos alunos, mais representativo será o resultado da escola. Acima de $85 \%$ é o ideal.

- Explicar o que é o padrão de desempenho: agrupamento de níveis de proficiência. Cada série apresenta o seu padrão e os cortes de cada padrão são determinados por cada secretaria de educação.

- Fazer o professor pensar nas práticas que poderiam servir de intervenção pedagógica nas escolas (RIO GRANDE DO SUL, 2014).
}

Apesar de outras empresas, autarquias ou fundações prestarem esses mesmos serviços, a hegemonia do CAEd neste "mercado das avaliações", impressiona. Por esse motivo, analisa-se algumas publicações vinculadas à esse Centro, procurando compreender melhor suas concepções. O CAEd tem amplo leque de serviços:

[...] que envolve a produção de uma série de materiais impressos - para gestores, professores, pesquisadores -, por meio de ações de formação desenvolvidas presencialmente e à distância, e da transferência de tecnologia para as secretarias de educação. (MELO, 2013, p.33)

Essa expansão se dá com um conjunto de desafios para a construção de "[...] uma cultura educacional comprometida com a eficácia do direito à educação [...]" (Melo, 2013, p.34). O mesmo se define como uma "[...] instituição que operacionaliza (elabora e desenvolve) programas estaduais e municipais destinados a mensurar o rendimento de estudantes das escolas públicas [...]" (CAEd, 2014).

Da mesma forma que outras empresas da área, o CAEd oferece seus serviços que envolvem várias atividades. O referido Centro além de implementar os sistemas de avaliação, também:

[...] cria e promove cursos de formação, qualificação e aprimoramento aos profissionais da Educação de diversos estados do Brasil, além de 


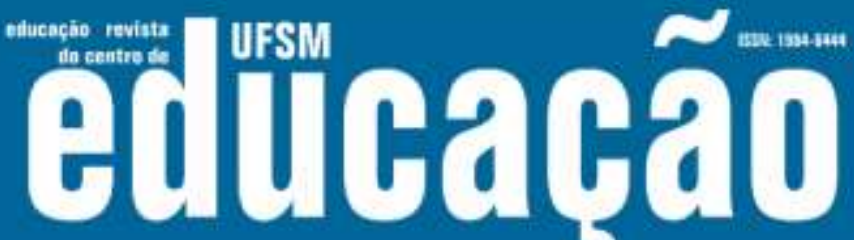

ISSN: 1984-6444 | http://dx.doi.org/10.5902/1984644434678

desenvolver software para a gestão de escolas públicas (como os projetos SisLAME e SIMADE) com o objetivo de modernizar a gestão educacional (CAEd, 2014).

Deve-se acrescentar às atividades do CAEd o oferecimento de apoio para outras fundações, tais como Fundação Roberto Marinho, Instituto Unibanco e Fundação Oi Futuro (CAEd, 2014).

O CAEd está organizado em cinco unidades que correspondem aos serviços oferecidos pela instituição, a saber: "Unidade de Pesquisa, Unidade de Avaliação, Unidade de Formação, Unidade de Sistemas de Gestão, Unidade de Administração" (CAEd, 2014). Esse Centro, além das avaliações estaduais também tem atuação junto às prefeituras municipais, estabelecendo parceria com ao menos dez cidades para a organização de avaliações externas e em larga escala próprias em suas redes de ensino ${ }^{14}$.

Além do CAEd, outras instituições e empresas prestam consultoria junto aos estados, oferecendo a elaboração, aplicação e correção das provas, bem como a elaboração de estratégias para as devolutivas dos resultados por meio de formações envolvendo diferentes instâncias das Secretarias de Educação. Estas empresas ou instituições também elaboram materiais para distribuição nas escolas, contendo os resultados das avaliações e informações sobre como trabalhar com esses dados, assim como os materiais elaborados pelo CAEd. Deve-se ressaltar que essas empresas fazem a defesa do modelo de avaliação como mecanismo para a melhoria da qualidade de educação e garantia do direito de aprendizagem.

Uma dessas empresas é a AVALIA que em seus materiais de divulgação, aponta para a busca de diferencial no mercado das avaliações, procurando "venderse" como alternativa:

Um importante diferencial da AVALIA a produção de relatórios completos e bem estruturados sobre as avaliações, destinados às escolas e às redes de ensino, com resultados consolidados, dados comparativos, contextualização das competências, aspectos socioculturais e níveis de proficiência. (AVALIA, 2014).

\footnotetext{
${ }^{14}$ Estabeleceram parcerias com o CAEd para criação de avaliação própria em suas redes municipais de ensino as cidades de Belo Horizonte (MG), Campo Grande (MS), Curitiba (PR), Florianópolis (SC), Ipojuca (PE), Maceió (AL), Ouro Branco (MG), Rio de Janeiro (RJ), Salvador (BA) e Teresina (PI).
} 


\section{Usm

ISSN: 1984-6444 | http://dx.doi.org/10.5902/1984644434678

Defendem a existência de uma relação direta entre as avaliações e a melhoria da qualidade da educação, orientada pelos materiais produzidos pela empresa:

Os relatórios são uma espécie de diagnóstico da escola com base no desempenho dos alunos e de sua percepção, assim como a dos pais, a dos professores e a da comunidade, sobre instituição de ensino. O objetivo é que esse material sirva para orientar as intervenções pedagógicas da instituição, levando à melhora da qualidade do ensino oferecido. É o instrumento que direciona o fechamento do ciclo: ensino, avaliação, desempenho, resultados, interpretação e, por fim, ação. (Avalia, 2014)

Estes relatórios são oferecidos como possibilidades de contração, num cardápio de serviços que oferecem informações diagnósticas das avaliações compostos por: Sumário Executivo, Relatório de Percepção da Escola pela Comunidade, Relatório de Frequências, Relatório da Escola (por ano avaliado) e Relatório de Rede.

Para esclarecer o que significam os resultados da avaliação educacional e institucional e propiciar que os números tenham aplicação pedagógica na instituição de ensino, a AVALIA possui um diferencial em suas devolutivas de resultados, entregando à escola as ferramentas capazes de direcionar o planejamento das ações. Dessa forma, a devolutiva se torna muito mais do que um ato de entrega de relatórios. (AVALIA, 2014)

Em que pese o esforço da AVALIA em se apresentar como inovadora no "mercado das avaliações", o CAEd também oferece as mesmas opções a seus contratantes. Denota-se, portanto, toda uma dedicação no sentido de ampliar a presença das avaliações no cotidiano das escolas, para além de elemento definidor das políticas públicas de gestão, pretende-se sua incorporação no planejamento e nas ações didáticas em sala de aula.

\section{Considerações Finais}

Demostra-se, neste texto, as influências de agentes privados nas concepções que permeiam os processos avaliativos em larga escala, ainda que a entidade com maior presença nesses processos seja uma fundação, sua atuação não difere em nenhum aspecto de outras instituições privadas que exercem influência na formulação e implementação de políticas por meio da prestação de serviços aos entes públicos, na forma de assessorias e consultorias, fenômeno, inclusive observado em outros países. Para Lima (2011), trata-se de acontecimentos explicado em parte pelas 


\section{Autuaŗão}

ISSN: 1984-6444 | http://dx.doi.org/10.5902/1984644434678

pressões de modernização guiadas por um referencial econômico-empresarial. Estas inviabilizam ou consideram ilegítima a ação do corpo técnico da própria administração pública.

No Brasil as avaliações externas e em larga escala introduziram nova lógica na gestão dos sistemas educacionais, marcada pelo controle centralizado do poder público sobre as práticas escolares.

Depreende-se, portanto, que empresas e fundações são responsáveis pela operacionalização das avaliações nos sistemas estaduais, constituindo um "mercado das avaliações", seja no âmbito do controle dos processos que adquire uma lógica privada, seja no controle da expertise para implementação das avaliações que também estão fora do controle da gestão dos sistemas de ensino.

Verifica-se que mesmo em estados que possuem capacidade técnica para elaboração de seu sistema de avaliação, constata-se a atuação de empresas e fundações, com predomínio do CAed, o que demonstra a preponderância dessas práticas como definidoras das políticas educacionais.

Ampliam-se os usos que se fazem das avaliações, como mecanismos de controle sobre as escolas e sobre o trabalho docente, sob uma lógica do mercado que passa a definir as políticas educacionais dos sistemas públicos.

Projeta-se para o futuro a ampliação desses mecanismos de controle privado sobre as políticas educacionais, a partir do avanço da financeirização que tende a acirrar os usos dos resultados dos testes para esse fim.

\section{Referências}

ADNETT, Nick; BOUGHEAS, Spiros; DAVIES, Peter. Market-based reforms of public schooling: some unpleasant dynamics. Economics of Education Review. Volume 21, Issue 4, August 2002, pp. 323-330. Disponível em: $<$ https://www.sciencedirect.com/science/article/pii/S0272775701000267 acesso em 26/11/2018. https://doi.org/10.1016/S0272-7757(01)00026-7>

ADRIÃO, Theresa; PERONI, Vera Maria Vidal. A educação pública e sua relação com o setor privado Implicações para a democracia educacional. Revista Retratos da Escola, Brasília, v. 3, n. 4, p. 107-116, jan./jun. 2009. Disponível em: $<$ http//www.esforce.org.br> Acesso em 15/02/2015. 


\section{usm Autlogha}

ISSN: 1984-6444 | http://dx.doi.org/10.5902/1984644434678

AFONSO, Almerindo Janela. Avaliação Educacional. Regulação e emancipação. 4ee․ São Paulo: Cortez, 2009.

AFONSO, Almerindo Janela. Estado, mercado, comunidade e avaliação: esboço para uma (re)articulação crítica". Revista Crítica de Ciências Sociais, n. 51, pp. 109-135. 1998.

ALAVARSE, Ocimar Munhoz; MACHADO, Cristiane; ARCAS, Paulo Henrique. Articulação entre qualidade e gestão da educação: as avaliações externas dos estados em questão. 37ª Reunião Nacional da ANPEd, 2015, UFSC. Disponível em: http://37reuniao.anped.org.br/wp-content/uploads/2015/02/Trabalho-GT05-4481.pdf. Acesso em 13-08-2015.

AVALIA. Produção de Relatórios. Disponível em: <http://www.avaliaeducacional.com.br/relatorios/>. Acesso em 18/10/2014.

BAUER, Adriana. Estudos sobre Sistemas de Avaliação Educacional no Brasil: um retrato em preto e branco. Revista @mbienteeeducação, Vol. 5, № 1. pp. 7-31, jan/jun, 2012.

BAUER, Adriana; REIS, Adriana Teixeira. Base de Dados Avaliação: balanço da produção teórica sobre avaliação de sistemas educacionais no Brasil: 1988 a 2011. São Paulo: Fundação Carlos Chagas, 2014. Disponível em: http://acervo.fcc.org.br

BAUER, Adriana; PIMENTA, Claudia Oliveira; HORTA NETO, João Luiz; SOUSA, Sandra Zakia Lian. Avaliação em larga escala em municípios brasileiros: o que dizem os números? Estudos em Avaliação Educacional, FCC. V. 26, ㄲo 62 . Maio/ ago 2015.

BAUER, Adriana; ALAVARSE, Ocimar Munhoz; OLIVEIRA, Romualdo Portela de. Avaliações em larga escala: uma sistematização do debate. Educ. Pesqui., São Paulo, v. 41, n. spe, p. 1367-1384, dez. 2015. Disponível em $<$ http://www.scielo.br/scielo.php?script=sci_arttext\&pid=S1517-

97022015001001367\&lng=pt\&nrm=iso>.

Acessos em 03 nov. 2018. http://dx.doi.org/10.1590/S1517-9702201508144607.BRASIL. Decreto no 6.094, de 24 de abril de 2007. Dispõe sobre a implementação do Plano de Metas Compromisso Todos pela Educação, pela União Federal, em regime de colaboração com Municípios, Distrito Federal e Estados, e a participação das famílias e da comunidade, mediante programas e ações de assistência técnica e financeira, visando a mobilização social pela melhoria da qualidade da educação básica. Diário Oficial da União 25 de abril de 2007.

CAEd. Quem Somos. Disponível em <http://institucional.caed.uff.br/quem-somos/>. Acesso em 11 de novembro de 2014.

CHIRINEA, Andréia Melanda; BRANDAO, Carlos da Fonseca. O IDEB como política de regulação do Estado e legitimação da qualidade: em busca de 


\section{Us:

ISSN: 1984-6444 | http://dx.doi.org/10.5902/1984644434678

significados. Ensaio: Aval. Pol. Públ. Educ., Rio de Janeiro , v. 23, n. 87, p. 461484, jun. 2015. Disponível em <http://www.scielo.br/scielo.php?script=sci_arttext\&pid=S0104-

$40362015000200461 \&$ lng $=$ pt\&nrm=iso>.

Acesso

em 03 nov. 2018. http://dx.doi.org/10.1590/S0104-40362015000100019.

FREITAS, Dirce Nei Teixeira de. A avaliação da educação básica no Brasil. Campinas. Autores Associados, 2007.

GIDDENS, Anthony. Para Além da Esquerda e da Direita. São Paulo: Editora UNESP, 1996.

GRUPO DE AVALIAÇÃO E MEDIDAS EDUCACIONAIS (GAME). A avaliação externa como instrumento da gestão educacional nos estados: relatório final. Belo Horizonte: Game/ Faculdade de Educação/Universidade Federal de Minas Gerais. Belo Horizonte: FAE/UFMG, ago. 2011.

INSTITUTO MILLENIUM. Voucher Educação - Livre para escolher e aprender. 2008. Disponível em <https://www.institutomillenium.org.br/artigos/vouchereducacao-livre-para-escolher-e-aprender/>. Acesso em 03/03/2018.

LE GRAND, Julian. Quasi-Markets and Social Policy. The Economic Journal. vol. 101, n. 408 (Sep., 1991), pp. 1256-1267. Disponível em https://www.jstor.org/stable/pdf/2234441.pdf?seq=1\#page_scan_tab_contents.

Acesso em 18/10/2018.LIMA, Licínio. Administração Escolar: Estudos. Porto: Porto Editora, 2011.

LOPES, Valéria Virgínia. Cartografia da Avaliação Educacional no Brasil. Tese. (Doutorado em Educação) Faculdade de Educação, USP, São Paulo, 2007.

MARTINS, Ângela Maria; SOUSA, Sandra Zákia Lian de. A produção científica sobre avaliação educacional e gestão de sistemas e de escolas: o campo da questão entre 2000 e 2008. Ensaio: avaliação de políticas públicas educacionais, Rio de Janeiro, v. 20, №. 74, jan./mar. p. 9-26. 2012.

MCGIMPSEY, Ian. Late neoliberalism: Delineating a policy regime. Critical Social Policy, vol. 37, n. 1. pp. 64-84. 2017. Disponível em: http://journals.sagepub.com/doi/pdf/10.1177/0261018316653552.

Acesso em: 27/10/2018.

MELO, Manuel Fernando Palácios da Cunha e. Atuação do CAed. 2013. Disponível em http://www.caed.ufjf.br/. Acesso em 01/04/2015.

OLIVEIRA, Romualdo Portela de. Qualidade com garantia de respeito à diversidades e necessidades de aprendizagem. In: GRACIANO, M. O Plano de desenvolvimento da educação (PDE). São Paulo: Ação Educativa, 2007. 


\section{Usm

ISSN: 1984-6444 | http://dx.doi.org/10.5902/1984644434678

OLIVEIRA, Romualdo Portela de. A transformação da educação em mercadoria no Brasil. Educ. Soc., Campinas, v. 30, n. 108, p. 739-760, out. 2009. Disponível em http://www.scielo.br/scielo.php?script=sci_arttext\&pid=S010173302009000300006\&l ng=pt\&nrm=iso. Acesso em 01 ago. 2018. http://dx.doi.org/10.1590/S010173302009000300006 .

ORELLANA, Víctor et al. La elección de escuela como fenómeno sociológico. Una revisión de literatura. Rev. Bras. Educ., Rio de Janeiro, v. 23, e230007, 2018. Disponível em <http://www.scielo.br/scielo.php?script=sci_arttext\&pid=S141324782018000100205\&lng=pt\&nrm=iso>. acesso em 29 out. 2018. Epub 01-Fev2018. http://dx.doi.org/10.1590/s1413-24782018230007.

PARÁ. VUNESP aplicará provas do SisPAE. Disponível em <http://www.seduc.pa.gov.br/portal/index.php?action=Destaque.show\&iddestaque=2 363\&idareainteresse $=1>$ Acesso em 2014.

PERBONI, Fabio. Avaliações externas e em larga escala nas Redes de Educação Básica dos Estados Brasileiros. 2016. 268f. Tese (Doutorado em Educação) Faculdade de Ciências e Tecnologia, Universidade Estadual Paulista, Presidente Prudente - SP.

PERONI, V. M. V.; OLIVEIRA, R. T. C. de, FERNANDES, M. D. E. Estado e terceiro setor: as novas regulações entre o público e o privado na gestão da educação básica brasileira. Educação \& Sociedade, v. 30 nำ108, 2009.

RIO GRANDE DO SUL. SAERS. Disponível em: http://www.educacao.rs.gov.br/pse/html/saers.jsp?ACAO=aca01. Acesso em 15 jan. 2014.

RISTOFF, Dilvo Ilvo. Princípios do Programa de Avaliação Institucional. In: BRASIL. Secretaria de Ensino Superior. Programa de Avaliação Institucional das Universidades Brasileiras. Brasília: SESu, 1994.

SINGER, Paul. Poder, política e educação. Revista Brasileira de Educação, vol. 1, ํㅜ 1. 1996,

SILVA, Itamar Mendes da. A Discussão sobre Avaliação nas Reuniões Anuais da ANPED no Período 2000 A 2010. Avaliação, Campinas; Sorocaba, SP, v. 18, n. 2, p. 335-350, jul. 2013

SOUSA, Sandra Zakia Lian de; OLIVEIRA, Romualdo Portela de. Políticas de avaliação da educação e quase mercado no Brasil. Educação e Sociedade, , vol.24, ำ. 84.2003

SOUSA, Sandra Zakia Lian de; OLIVEIRA, Romualdo Portela. Sistemas estaduais de avaliação: uso dos resultados, implicações e tendências. Cadernos de Pesquisa, v.40, n.141, p.793-822, set./dez. 2010. 


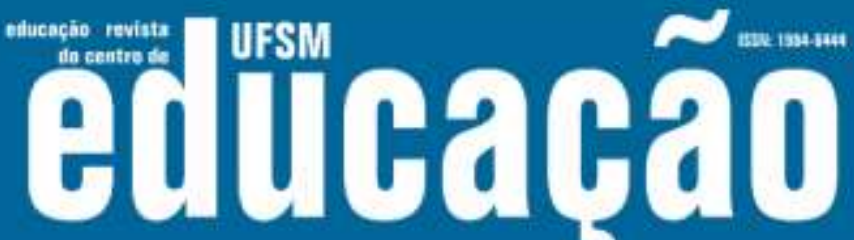

ISSN: 1984-6444 | http://dx.doi.org/10.5902/1984644434678

SVERDLICK, Ingrig. ¿Que hay de nuevo en avaluación educativa? Buenos Aires: Noveduc Libros, 2012.

TERRASECA, Manuela. Autoavaliação, avaliação externa... Afinal para que serve a avaliação das escolas?. Cad. CEDES, Campinas, v. 36, n. 99, p. 155174, ago. 2016. $\quad$ Disponível em <http://www.scielo.br/scielo.php?script=sci_arttext\&pid=S0101-

32622016000200155\&lng=pt\&nrm=iso>. Acesso em 01 nov. 2018. http://dx.doi.org/10.1590/CC0101-32622016160581.

WERLE, Flavia Obino Corrêa. Avaliação em Larga Escala: questões polêmicas. Brasília: Liber Livros, 2012.

\section{Correspondência}

Fabio Perboni - Professor doutor da Universidade Federal da Grande Dourados, Dourados, Mato Grosso do Sul, Brasil.

Andréia Nunes Militão - Professora doutora da Universidade Estadual de Mato Grosso do Sul, Dourados, Mato Grosso do Sul, Brasil.

Cristiano Amaral Garboggini Di Giorgi - Professor doutor da Universidade do Oeste Paulista, Presidente Prudente, São Paulo, Brasil.

Faculdade de Educação da Universidade Federal da Grande Dourados. R. João Rosa Góes, 1761, Vila Progresso. CEP: 79825-070, Dourados, Mato Grosso do Sul, Brasil.

E-mail: fabioperboni@ufgd.edu.br - andreiamilitao@uems.br - utopico92@gmail.com Recebido em 04 de setembro de 2018 Aprovado em 05 de fevereiro de 2019

\section{(ब) (1) \&}

The is work is licensed under a Creative Commons Attribution-NonCommercial 4.0 International (CC BY-NC 4.0) 